\title{
INTUSSUSCEPTION IN ADULT MALE
}

\section{Govind Trivedi ${ }^{1}$, Rajeev Bhargava ${ }^{2}$, Manukant Bhatnagar ${ }^{3}$}

${ }^{1}$ Associate Professor, Department of Surgery, Rama Medical College Hospital and Research Centre, Mandhana.

2 Professor, Department of Surgery, Rama Medical College Hospital and Research Centre, Mandhana.

3Intern, Department of Surgery, Rama Medical College Hospital and Research Centre, Mandhana.

HOW TO CITE THIS ARTICLE: Trivedi G, Bhargava R, Bhatnagar M. Intussusception in adult male. J. Evolution Med. Dent. Sci. 2017;6(80):5674-5675, DOI: 10.14260/jemds/2017/1230

\section{BACKGROUND}

Intussusception is highly uncommon in adults and accounts for $5 \%$ of all reported cases, Dean DL et al ${ }^{[1]}$ and Gayer G, and Apter $\mathrm{S}^{[2]}$ compared to children, where it is more often encountered. A definite identifiable bowel lesion, e.g. polyp, tumour, diverticulum and foreign body is found in $90 \%$ of cases. In remaining $10 \%$, the cause is idiopathic. Diagnosis is difficult because of non-specific symptoms and its rarity, Han AM et al.[3] Diagnostic modalities include-

1. Radiography.

2. Ultrasonography.

3. Computed tomography.

We present the case of an adult male patient with no previous operations, no underlying pathology of intestine.

\section{PRESENTATION OF CASE}

We present the case of a 24 year old male patient from rural background. He presented to our emergency department complaining of peri-umbilical pain for several days.

The pain was moderate in severity and colicky in nature associated with nausea and vomiting.

There was no remarkable previous history.

\section{CLINICAL DIAGNOSIS}

Abdominal examination revealed a soft-firm mass around the umbilicus with moderate tenderness; however, no rebound tenderness or abdominal guarding was present. Bowel sounds were increased and rectal examination was normal. The patient looked pale and dehydrated with tachycardia and blood pressure towards lower side.

Biochemistry and blood counts were within normal range. Radiograph revealed ileus of small intestine without any gas under diaphragm. USG revealed only dilated bowel loops. A contrast enhanced CT confirmed the finding of small bowel intussusception.

'Financial or Other Competing Interest': None.

Submission 28-08-2017, Peer Review 22-09-2017,

Acceptance 28-09-2017, Published 05-10-2017.

Corresponding Author:

Dr. Govind Trivedi,

Rama Medical College Hospital and

Research Centre,

Mandhana,

Kanpur.

E-mail:govind_trivedi03@yahoo.co.uk

DOI: $10.14260 /$ jemds/2017/1230

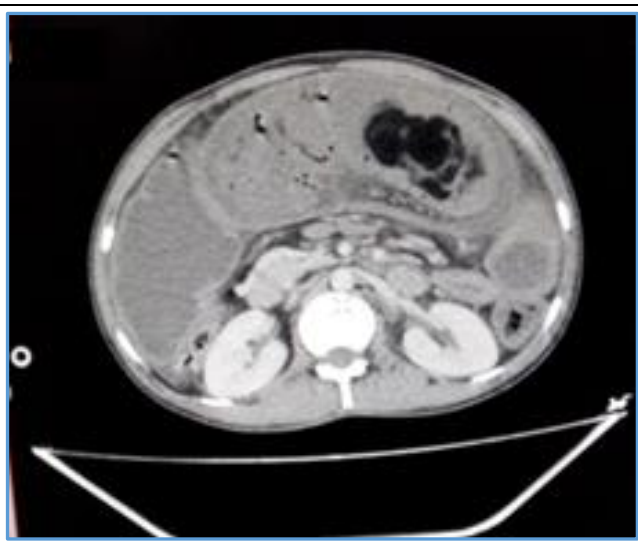

Figure 1. CT showing Small Bowel Intussusception

\section{DIFFERENTIAL DIAGNOSIS}

Intussusception is relatively rare in adult population and this along with the vague clinical feature makes diagnosis difficult, Karamercan A, Kurukahvecioglu 0.[4] Causes of intussusception can be divided into four groups, Agha F.[5]:

1. Tumour related.

2. Post-operative.

3. Miscellaneous (Meckel's diverticulum, coeliac disease).

4. Idiopathic.

\section{PATHOLOGICAL DIAGNOSIS}

The resected portion was sent for histopathological examination, which did not reveal any remarkable cause for intussusception.

\section{DISCUSSION OF MANAGEMENT}

Exploratory laparotomy was done, which revealed a massive ileo-ileal intussusception involving more than 7 feet of bowel. Manual reduction was done and entire length of bowel including intussusception and intussuscepiens was found to be gangrenous. Merine D, Fishman EK, Jones B, Siegelman SS[6]

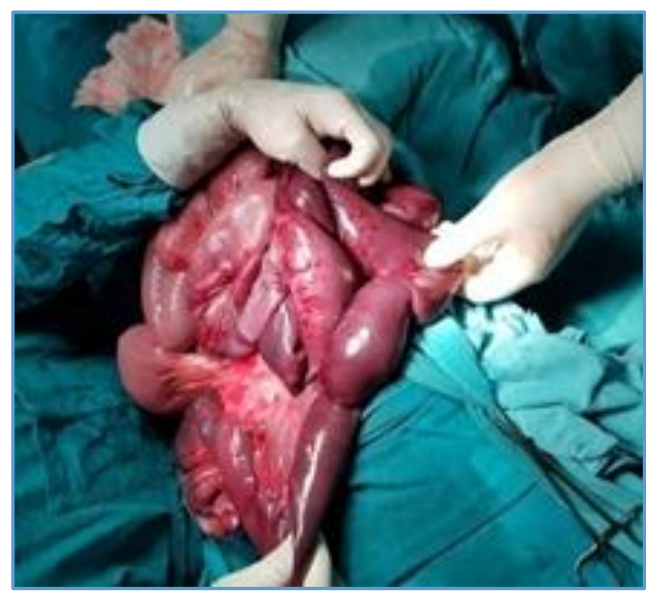

Figure 2. Reduction of Intussusception 
Resection of the non-viable part of ileum was done (7FT). Since the oedema and necrotic condition plus the general condition of the patient prevented us from primary anastomosis. A proximal end ileostomy was done with closure of distal loop. Nagorney DM, et al.[7]

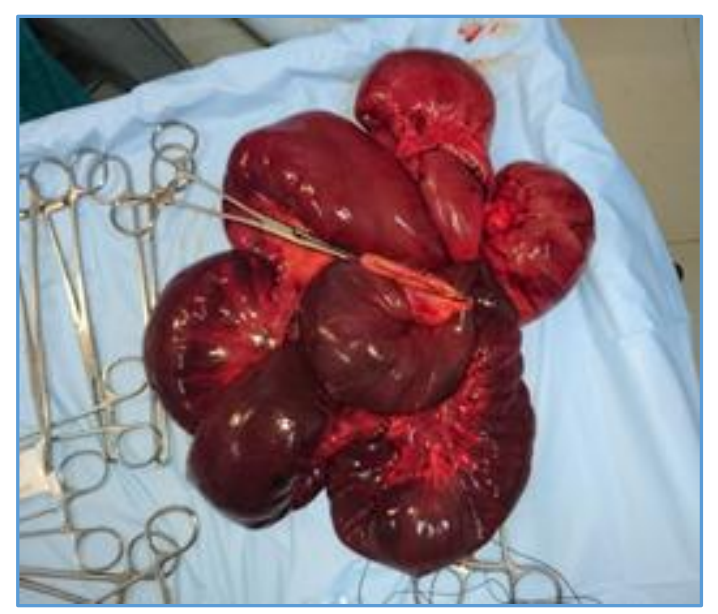

Figure 3. Resected Bowel Segment (7 ft)

\section{FINAL DIAGNOSIS}

Although, the mechanism that lead to an intussusception is still unknown, any lesion or irritation of the bowel wall or lumen that de-synchronises the peristaltic waves could provide the mechanical cause for invagination of one part of intestine into another.

Since the existence of a tumour, polyp, diverticulum or adhesions due to preceding operation were excluded as far as our patient was concerned, it can be speculated that dysrhythmic peristalsis may be the cause of intussusception.
Only rarely can we detect adult intussusception in the absence of underlying pathology. Aston SJ, et al.[8]

It still remains to be investigated to fully understand the pathomechanism of idiopathic intussusception. CT scan can be of great value in diagnosis as it reveals the site, level and cause of obstruction and also displays the signs of threatening bowel viability. Marshak RH,[9] Merine D.[6]

However, idiopathic intussusception should form a part of curriculum in emergency room to rule out obstruction in young adult.

\section{REFERENCES}

[1] Dean DL, Henry Ellis F, Sauer WG. Intussusception in adults. Arch Surg 1956;73(1):6-11.

[2] Gayer G, Apter S, Hofmann C, et al. Intussusception in adults: CT diagnosis. Clin Radiol 1998;53(1):53-7.

[3] Reijnen HA, Joosten HJ, de Boer HH. Diagnosis and treatment of adult intussusception. Am J Surg 1989;158(1):25-8.

[4] Karamercan A, Kurukahvecioglu O, Yilmaz TU, et al. Adult ileal intussusception: an unusual emergency condition. Adv Ther 2006;23(1):163-8.

[5] Agha FP. Intussusception in adults. AJR Am J Roentqenol 1986;146(3):527-31.

[6] Merine D, Fishman EK, Jones B, et al. Enteroenteric intussusception: CT findings in nine patients. AJR 1987;148(6):1129-32.

[7] Nagorney DM, Sarr MG, Mcllrath DC, et al. Surgical management of intussusception in the adult. Ann Surg 1981;193(2):230-6.

[8] Aston SJ, Machlfeder HI. Intussusception in the adult. Am Surg 1975;41(9):576-80.

[9] Margulis AR. Radiology of the small intestine. Calif Med 1970;113(3):109-10. 